\title{
Association between Pretreatment Levels of Serum Vascular Endothelial Growth Factor (VEGF) and Survival Outcomes in Locally Advanced Cervical Cancer Patients*
}

\author{
Kanyarat Katanyoo", Kanisa Rongsriyam, Marisa Chongtanakon \\ Radiation Oncology Section, Department of Radiology, Faculty of Medicine Vajira Hospital, Navamindradhiraj University, Bang- \\ kok, Thailand. \\ Email: ${ }^{\#}$ Kankatanyoo@edu.vajira.ac.th
}

Received November $18^{\text {th }}, 2013$; revised December $8^{\text {th }}, 2013$; accepted December $15^{\text {th }}, 2013$

Copyright (C) 2013 Kanyarat Katanyoo et al. This is an open access article distributed under the Creative Commons Attribution License, which permits unrestricted use, distribution, and reproduction in any medium, provided the original work is properly cited. In accordance of the Creative Commons Attribution License all Copyrights (C) 2013 are reserved for SCIRP and the owner of the intellectual property Kanyarat Katanyoo et al. All Copyright (C) 2013 are guarded by law and by SCIRP as a guardian.

\begin{abstract}
Objective: To evaluate the association between pretreatment levels of serum vascular endothelial growth factor (VEGF) and long-term treatment outcomes in patients with locally advanced cervical cancer (LACC). Methods: Thirty-nine patients diagnosed with LACC (stage IIB-IVA) and obtaining blood for serum VEGF were identified. All patients received complete treatment as radical radiotherapy with or without concurrent chemotherapy. Surveillance for all patients was every 3 months during the first 2 years, and every 6 months later. Results: Mean age of 39 patients was 52.3 \pm 10.8 years old. Twenty-three patients $(59.0 \%)$ had stage IIB, and 16 patients $(41.0 \%)$ had stage IIIB. Histological cell type was mostly squamous cell carcinoma $(89.7 \%)$. The median and $75^{\text {th }}$ percentile level of serum VEGF were 610.2 $\mathrm{pg} / \mathrm{ml}(0.0-4067.2 \mathrm{pg} / \mathrm{ml})$ and $825.6 \mathrm{pg} / \mathrm{ml}$, respectively. At median follow-up of 37.0 months (range, $26.8-46.3$ months), the 3 -year OS rate was $78.6 \%$. Clinical stage $(p=0.04)$ and $75^{\text {th }}$ percentile of VEGF level $(p=0.04)$ were impacted on OS in univariable analysis. The 3-year OS of patients in stage IIB with serum VEGF of $\leq 825.6 \mathrm{pg} / \mathrm{ml}$ and of $>825.6 \mathrm{pg} / \mathrm{ml}$ was slightly different, $94.4 \%$ and $80.0 \%$ respectively $(\mathrm{p}=0.34)$, whereas there were many differences in stage IIIB, $71.4 \%$ and $25.0 \%$ in patients with serum VEGF of $\leq 825.6 \mathrm{pg} / \mathrm{ml}$ and of $>825.6 \mathrm{pg} / \mathrm{ml}$ respectively $(\mathrm{p}=$ 0.05). Conclusion: High pretreatment serum VEGF level has an influence on OS for LACC. It is potentially used as a predictive factor, especially in patients stage IIIB, in order to provide efficient treatment and improve survival outcomes in the future.
\end{abstract}

Keywords: Serum VEGF; Locally Advanced Cervical Cancer; Overall Survival

\section{Introduction}

Although screening program is well known for prevention in cervical cancer, the incident rate of this cancer is still high. In developing countries including Thailand, cervical cancer is the second most common cancer in women [1]. For locally advanced stage (IIB-IVA), concurrent chemoradiation (CCRT) is the standard treatment. However, the treatment outcome is fair, which is just $60 \%-65 \%$ in terms of 5 -year overall survival [2]. An important meta-analysis study found that CCRT had less influence on advanced stages, while distant failure was

${ }^{*}$ Conflict of interest: All authors declared no conflict of interest.

${ }^{*}$ Corresponding author. still the major problem of these patients [3]. Several mechanisms are involved in that failure which seems unlikely to be controlled by CCRT.

New blood vessels have the significant role for tumor cell proliferation and metastasis to distant organs. When hypoxia has occurred in tumor cell, it can stimulate hypoxia-inducible transcription factors (HIFs) and signalise to secret angiogenic factors [4]. One of the important angiogenic factors is vascular endothelial growth factor (VEGF), which has been determined to be considerable protein for complicated mechanisms of tumor vessel formation $[4,5]$. For cervical cancer, several literatures were interested in the correlation of serum VEGF with clinicopathological findings [6-14]. According to those 
results, serum VEGF was related with staging or advance of disease [6,8-12,14]. However, some conflictions of results were shown from two Asian studies [7,13]. For the association of this serum with long-term treatment outcomes in regard to progression-free survival (PFS) and overall survival (OS), few studies had reported these issues with inconsistent conclusions [8,9,11].

In 2011 , we reported a prospective study which focused on the association of pretreatment serum VEGF with clinicopathology and response of treatment by radical radiotherapy with or without concurrent chemotherapy in stage IIB-IVA cervical cancer patients. The results showed no correlation of serum VEGF level with stage and tumor size, but patients who had persistent disease had a trend of higher level of this serum than patients who had complete response to disease after complete treatment [13]. The objective of this study is to report the relationship of pretreatment serum VEGF in those patients with long-term treatment outcomes in terms of 3-year PFS and OS.

\section{Material and Methods}

\subsection{Patients}

After an approval from the Institutional Review Board (IRB) of Faculty of Medicine Vajira Hospital, Navamindradhiraj University, we enrolled patients who were diagnosed as locally advanced stage (stage IIB-IVA) of cervical cancer, and had squamous or adenocarcinoma as cell type. Between January 2009 and June 2010, 40 patients were included with obtaining inform consent for the first time. Blood specimens for serum VEGF were taken before starting radical radiotherapy about 24 hours. All detail of measurement of serum VEGF was shown in our previous study [13]. Radical radiation therapy with or without concurrent chemotherapy were performed for 39 patients, while one patient refused to receive treatment. The median and $75^{\text {th }}$ percentile of pretreatment level of serum VEGF for those rest patients who were participated in present study were $610.2 \mathrm{pg} / \mathrm{ml}(0.0-4067.2$ $\mathrm{pg} / \mathrm{ml}$ ) and $825.6 \mathrm{pg} / \mathrm{ml}$, respectively.

\subsection{Treatments}

Radical radiotherapy composed of external beam pelvic radiotherapy at a total dose of 54 - 60 Gy applied in daily fractions of $1.8-2.0 \mathrm{~Gy}$. Three to five fractions of intracavitary (ICRT) high dose-rate brachytherapy were applied on weekly fractions of $6.0-7.2$ Gy each to point A, depending on tumor volume. Using weekly cisplatin or carboplatin in a concurrent setting depended on each physician. Weekly dosages of cisplatin or carboplatin were $40 \mathrm{mg} / \mathrm{m}^{2}$ and 2AUC, respectively, with appropriate pre-medications were given. Follow-up for all patients was based on physical examination. At last time of ICRT, all patients were follow-up at one month and two months afterwards to evaluate response of treatment. Tumor or suspected diseases that were still seen at cervix in the third month were defined as persistent disease and taken biopsy. Surveillance for all patients was every 3 months during the first 2 years, and every 6 months after that. PFS and OS which were the main objectives in this study were ascertained. PFS was defined as interval from the first date of radical radiotherapy to the time of disease recurrence in pelvis, metastasis to other organs, or death. For the patients who were lost to follow-up, PFS data was right censored at the time of the last evaluation, or contact when the patients were known to be progressionfree. OS was defined as time from the first date of treatment to the date of death. For patients who were alive at the end of study, survival data were right-censored at the date of last follow-up visit. Written inform consent was provided by all patients whose data were used to analyze again.

\subsection{Statistical Analysis}

Data were analyzed by using SPSS statistical software, version 11.5 (SPSS Inc., Chicago, IL). Descriptive statistic was used to analyze clinicopathological data, which was summarized as number and percentage. Normal distribution of serum VEGF levels was tested using the Kolmogorov-Smirnov test. OS and PFS were analyzed by the Kaplan-Meier method. Univariable analysis was used to compare between groups with log-rank test. A two sided P-value $<0.05$ were considered statistically significance.

\section{Results}

Mean age of 39 patients was $52.3 \pm 10.8$ years. Twentythree patients $(59.0 \%)$ had stage IIB, and 16 patients $(41.0 \%)$ had stage IIIB. Histological cell type was mostly squamous cell carcinoma (89.7\%). Except two patients who were got treatment as radical radiotherapy alone, almost of all patients received concurrent chemoradiation (CCRT). Twenty-three patients from 37 patients $(62.2 \%)$ had weekly carboplatin for concurrence with external radiation therapy, while weekly cisplatin was used for 14 remaining patients. All patients received complete treatment as plan and were assessed response rate at 3 months after the last fraction of ICRT. Nearly $95.0 \%$ of patients had achieved complete response. All other details of clinicopathology and correlation with pretreatment serum VEGF level were demonstrated at our prior study [13].

From a median follow-up of 37.0 months (range, 26.8 - 46.3 months), eight patients (20.5\%) died from disease and one patient $(2.6 \%)$ was alive with disease. Disease 
progression were identified as local recurrence in one (2.6\%), distant metastasis in three (7.7\%), and both pelvic and distant failure in four (10.2\%). Lung (3 patients, $7.7 \%$ ) and paraaortic node (3 patients, 7.7\%) were the most common sites of distant failure. The other sites of distant organ metastasis were supraclavicular lymph node (one patient, 2.6\%), bone (one patient, 2.6\%) and inguinal lymph node (one patient, $2.6 \%$ ). When the median of pretreatment serum VEGF $(610.2 \mathrm{pg} / \mathrm{ml})$ was used for being the cut-off level, 6/9 patients $(66.7 \%)$ who had disease progression had VEGF levels higher than that level. However, $14 / 30$ patients $(46.7 \%)$ who were still alive without any evidence of disease also had VEGF levels higher than the median level. There was no significant difference of this cut-off level $(p=0.45)$. On the one hand, when we used the $75^{\text {th }}$ percentile of pretreatment level of serum VEGF $(825.6 \mathrm{pg} / \mathrm{ml})$ to be the cut-off value, $4 / 9$ patients $(44.4 \%)$ with recurrence of diseases and $5 / 30$ patients $(16.7 \%)$ with no evidence of disease had serum VEGF levels more than this level. The value of $75^{\text {th }}$ percentile had a trend of association with status of disease, but there was no statistically signifycance $(\mathrm{p}=0.08)$.

At the time of analysis, median PFS and OS had not been reached. The 3-year PFS and OS rates were 76.9\% and $78.6 \%$, respectively. In univariable analysis, clinical stage was the only significant factor on 3-year PFS rate $(p=0.02)$, whereas serum VEGF at cut-off value of $75^{\text {th }}$ percentile had a high tendency to be an influential factor $(\mathrm{p}=0.06)$. For 3 -year OS, the $75^{\text {th }}$ percentile of VEGF level became to be one of two important factor $(p=0.04)$ besides clinical stage (Figure 1). However, the cut-off point at median VEGF level did not show any correlation with both PFS and OS (Table 1). When we classified the $75^{\text {th }}$ percentile of VEGF level by each clinical stage, 3year OS of patients in stage IIB with serum VEGF $\leq$ $825.6 \mathrm{pg} / \mathrm{ml}$ and $>825.6 \mathrm{pg} / \mathrm{ml}$ was $94.4 \%$ and $80.0 \%$, respectively. This difference did not reach statistical significance $(p=0.34)$. Kaplan-Meier curve could not be done, because there was only one event in each group of two different VEGF levels in stage IIB. The interesting point was noted in patients in stage IIIB with serum VEGF $>825.6 \mathrm{pg} / \mathrm{ml}$. We found that patients in this group had poor survival outcome, 3-year OS was $25.0 \%$, while 3-year OS of patients in the same stage with serum $\leq 825.6 \mathrm{pg} / \mathrm{ml}$ was $71.4 \%$. Moreover, median survival of patients who had serum VEGF $>825.6 \mathrm{pg} / \mathrm{ml}$ was 14.0 months $(95 \%$ confidence interval $[\mathrm{CI}]=7.0-21.0$ months). Three out of 4 patients in this group developed distant metastasis and died from disease. While median survival of another group (serum VEGF $\leq 825.6 \mathrm{pg} / \mathrm{ml}$ ) had not been reached yet. The difference of survival outcome from this using cut-off value in patients with stage IIIB was quite remarkable. Due to small number of patients, the statistic difference was reached marginally significant $(\mathrm{p}=0.05)$ (Figure 2).

\section{Discussion}

In current study, we found that serum VEGF at pretreatment time in locally advanced cervical cancer has some correlations with survival outcomes. The first point need to be emphasized is an appropriate cut-off value. To date, there is no standard level or recommendation for this

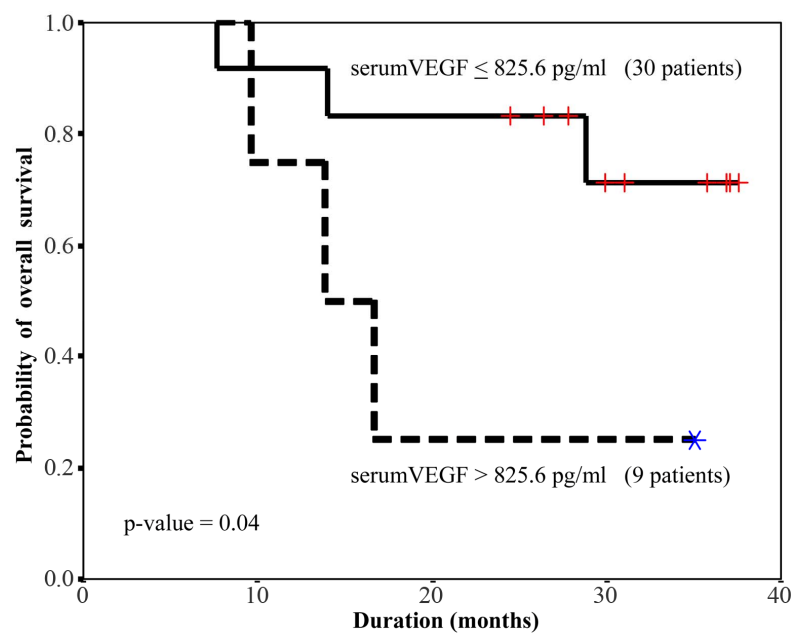

Figure 1. Overall survival when stratified by the $75^{\text {th }}$ percentile of serum VEGF for all clinical stages (39 patients).

Table 1. Univariable analysis of prognostic factors for survival outcomes in locally advanced cervical cancer patients.

\begin{tabular}{|c|c|c|c|c|}
\hline Prognostic factor & 3-yr PFS (\%) & p-value & 3-yr OS (\%) & p-value \\
\hline Tumor size $(\leq 4 \mathrm{~cm} \mathrm{vs}>4 \mathrm{~cm})$ & 85.7 vs 66.7 & 0.13 & 88.9 vs 66.7 & 0.06 \\
\hline Histological cell type (SCCA vs ACA) & 77.1 vs 75.0 & 0.89 & 79.1 vs 75.0 & 0.79 \\
\hline Clinical stage (IIB vs IIIB) & 91.3 vs 56.2 & $0.01^{*}$ & 91.3 vs 60.1 & $0.04^{*}$ \\
\hline Median of serum VEGF $(\leq 610.2 \mathrm{pg} / \mathrm{ml} \mathrm{vs}>610.2 \mathrm{pg} / \mathrm{ml})$ & 84.2 vs 70.0 & 0.23 & 87.4 vs 70.0 & 0.12 \\
\hline $75^{\text {th }}$ percentile of serum VEGF $(\leq 825.6 \mathrm{pg} / \mathrm{ml}$ vs $>825.6 \mathrm{pg} / \mathrm{ml})$ & 83.3 vs 55.6 & 0.06 & 85.3 vs 55.6 & $0.04^{*}$ \\
\hline
\end{tabular}

Abbreviation: PFS, progression-free survival; OS, overall survival; SCCA, squamous cell carcinoma; ACA, adenocarcinoma; VEGF, vascular endothelial growth factor. 


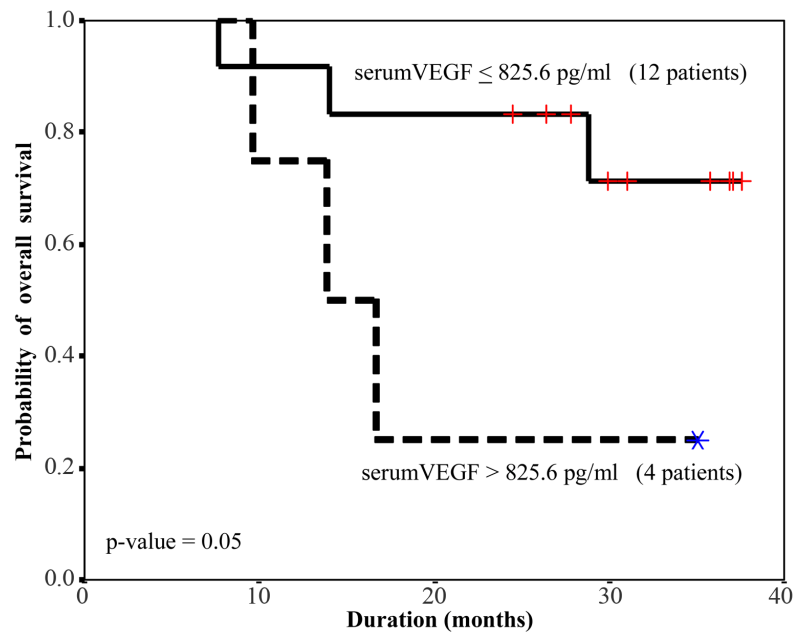

Figure 2. Overall survival when stratified by the $75^{\text {th }}$ percentile of serum VEGF in stage IIIB disease (16 patients).

issue. Therefore, we used two different levels in our study. The first selected level was the median of serum VEGF level $(610.2 \mathrm{pg} / \mathrm{ml})$, that was used in study of Bachtiary [9] and Zusterzeel [11]. However, our finding of this cut-off level did not show any relationship with PFS and OS. The difference of our results from two previous studies was observed. Bachitary et al. demonstrated that when serum VEGF level was more than 244 $\mathrm{pg} / \mathrm{ml}$ (median point of serum VEGF in their study), tumor radioresistance from radiation therapy were showed and had the effect on survival outcomes. However, they did not describe the detail in regard to area of treatment failure [9]. The Landmark study of serum VEGF in cervical cancer came from the Netherlands. They reported that serum VEGF at median level in their study (540 $\mathrm{pg} / \mathrm{ml}$ ) was a prognostic factor to predict both PFS and OS. The majority of their patients were in early stage (100 of stage IB and 32 of stage IIA). While the number of patients in stage IIB-IV which was the targeted group in our study was 35 patients (19 of stage IIB, 11 of stage III, and 5 of stage IV). As a consequence of these small numbers, they could not demonstrate statistical difference when analyses were taken place in each stage [11].

The second challenging point was the level of the $75^{\text {th }}$ percentile of serum VEGF $(825.6 \mathrm{pg} / \mathrm{ml})$. This level was used in the study of Lebrecht [8]. At this level, there was a significant difference in 3-year OS between patients who had serum VEGF level $\leq 825.6 \mathrm{vs}>825.6 \mathrm{pg} / \mathrm{ml}$ (p $=0.04$ ). Due to our previous study, we found that there were no any associations of serum VEGF level with tumor stage [13]. Therefore, in order to evaluate that whether those results still existed, we stratified level of the serum VEGF $(\leq 825.6 \mathrm{vs}>825.6 \mathrm{pg} / \mathrm{ml}$ ) by clinical stage (stage IIB vs stage IIIB). The notable issue was seen in patients in stage IIIB with serum VEGF higher than $825.6 \mathrm{pg} / \mathrm{ml}$. Patients in this group had the deterioration of 3-year OS which was approximately three times lower when compared with another group $(25.0 \%$ vs $71.4 \%$ ). Although statistical significance could not be reached, the vast difference should be emphasized. The effect of using this level to be the cut-off value did not produce results in the same way as seen in Lebrecht et al. who chose the $75^{\text {th }}$ percentile of serum VEGF level (319.4 pg/ml) for cut-off value [8]. They found no correlation between high serum level at that value with PFS and OS.

The problem concerning the proper cut-off value of serum VEGF remains to be obscure and debated. Nowadays, our study was the fourth study which reported serum VEGF with long term treatment outcomes including PFS and OS in cervical cancer (Table 2). There is high diversity of serum VEGF levels observed among four studies. Some reasonable explanations may include various stages of disease (stage I - IV) and proportion of each stage included in each study. Previous three studies had enrolled patients in all stages, and that might deliver wide range of VEGF level. Although the cut-off level used in all studies was the same level, median or $75^{\text {th }}$ percentiles, the real figures among those four studies showed wide distribution as well as inconsistence. The median value of serum VEGF in our study was the highest value amongst all studies, because we included only advanced stage. Therefore, there was no dilutional effect of this serum from early disease like previous three studies.

We concern that the limitation in this study was the number of patients which was not enough to make the difference for statistical analysis, especially in stage IIIB. However, the potential advantage of serum VEGF in that stage is rather explicit. Patients who had two poor prognostic factors, both stage IIIB and serum VEGF level of $>825.6 \mathrm{pg} / \mathrm{ml}$, had a higher chance of distant metastasis and death rate than patients in the same stage with serum VEGF level $\leq 825.6 \mathrm{pg} / \mathrm{ml}$. At the recent year, Chemoradiotherapy for Cervical Cancer Meta-analysis Collaboration (CCCMAC) concluded that CCRT had the benefit over RT in all stages. However, they found that the benefit of 5-year OS was compromised from CCRT when increasing stage of disease was appeared, $7 \%$ in stage IIB and only $3 \%$ in stage IIIB. Moreover, area that CCRT had fewer efficacies was distant organs and affected on distant metastasis [3]. However, patients in stage IIIB who did not gain much benefit from CCRT, we did not know that whether it would have association with serum VEGF. These evidences suggest that for patients in locally advanced stage, they should get more aggressive treatment than CCRT to salvage some occult metastatic diseases. 
Table 2. Studies of serum VEGF with survival outcomes.

\begin{tabular}{|c|c|c|c|c|c|c|}
\hline Author [ref] & Stage & $\begin{array}{c}\text { Number of } \\
\text { patients (\%) }\end{array}$ & $\begin{array}{c}\text { Median } \\
\text { (pg/ml) (range) }\end{array}$ & Cut-off value & Outcomes & $\begin{array}{l}\text { Median FU } \\
\text { time (months) }\end{array}$ \\
\hline 1. Lebrecht $[8]$ & $\begin{array}{l}\text { IA } \\
\text { IB } \\
\text { IIA } \\
\text { IIB } \\
\text { III } \\
\text { IV }\end{array}$ & $\begin{array}{c}9(10.7 \%) \\
23(27.4 \%) \\
6(7.1 \%) \\
33(39.3 \%) \\
11(13.1 \%) \\
2(2.4 \%)\end{array}$ & $\begin{array}{c}319.4 \\
(59.5-1849.1)\end{array}$ & $\begin{array}{l}\text { - The } 75^{\text {th }} \text { percentile } \\
(581.7 \mathrm{pg} / \mathrm{ml})\end{array}$ & No difference on PFS and OS & 21.3 \\
\hline 2. Bachitary [9] & $\begin{array}{l}\text { IB - II } \\
\text { III - IVA }\end{array}$ & $\begin{array}{l}18(64.3 \%) \\
5(21.7 \%)\end{array}$ & $\begin{array}{c}244.0 \\
(31.9-817.6)\end{array}$ & - Median & $\begin{array}{l}\text { Difference in PFS } \\
\quad(p=0.003)\end{array}$ & 25.0 \\
\hline 3. Zusterzeel [11] & $\begin{array}{c}\text { IB } \\
\text { IIA } \\
\text { IIB } \\
\text { III/IV }\end{array}$ & $\begin{array}{c}100(59.9 \%) \\
32(19.1 \%) \\
19(11.4 \%) \\
16(9.6 \%)\end{array}$ & $\begin{array}{c}540.0 \\
(280.0-1260.0) \\
\text { Early stage: } 440.0 \\
\text { Advanced stage: } 1040.0\end{array}$ & - Median & $\begin{array}{l}\text { Difference in } \\
\text { PFS }(p=0.010) \text { and } \\
\text { OS }(p=0.006)\end{array}$ & NA \\
\hline 4. This study & $\begin{array}{l}\text { IIB } \\
\text { IIIB }\end{array}$ & $\begin{array}{l}23(59.0 \%) \\
16(41.0 \%)\end{array}$ & $\begin{array}{c}610.2 \\
(0.0-4067.2)\end{array}$ & $\begin{array}{l}\text { - Median } \\
(825.6 \mathrm{pg} / \mathrm{ml})\end{array}$ & $\begin{array}{l}\text { - Median } \\
\text { - No difference on PFS }(\mathrm{p}=0.234) \text { and } \\
\text { OS }(\mathrm{p}=0.116) \\
\text { The 75th percentile } \\
\text { - No difference on 3-year PFS }(\mathrm{p}=0.061) \\
\text { - Difference in 3-year OS }(\mathrm{p}=0.042)\end{array}$ & 37.0 \\
\hline
\end{tabular}

Abbreviation: NA, Not available.

At the present time, there is no standard serologic tumor marker in cervical cancer [15]. The most potential serum assay to be used at follow-up may be squamous cell carcinoma antigen (SCC) $[15,16]$. This marker has been studies the most when compared to others such as: cytokeratin fragment (CYFRA 21-1), CA 125 and VEGF. However, one problem seen in using SCC antigen is similar to serum VEGF. The wide range of rising rate appeared, $28 \%-88 \%$, due to some differences of the cut-off value chosen [15]. However, the important thing which we should be concerned is whether these serums can improve survival outcomes of patients. As a result of recurrent or metastatic disease of cervical cancer patients, there is no any curative treatment for them. All treatments are aimed as palliation. Hence, in locally advanced diseases which are known that CCRT is not adequate to control occult distant metastasis, more suitable treatments should add more in appropriate patients. The accurate serum tumor marker for prediction survival outcomes may be used to evaluate these patients for receiving more aggressive treatment than CCRT at the first time of treatment.

During the past decade, role of VEGF targeted therapy was mentioned in gynecologic malignancies [17]. Most studies concentrated on ovarian cancer, while a few trials of cervical cancer are ongoing. Two phase II studies involved using VEGF inhibitor at concurrent time with RT and platinum-based chemotherapy. Since it takes years to achieve the final outcomes of cancer treatment in terms of PFS or OS, all answers about the role of VEGF inhibitor in cervical cancer are still inconclusive. Moreover, we do not know whether serum VEGF can be used as an indicator to follow-up treatment outcomes after patients have obtained anti-VEGF drug. In breast cancer, human epidermal growth factor receptor type 2 (HER-2/neu) is one of the predictive factors. Trastusumab is the wellknown targeted therapy for treatment in patients with HER-2/neu positive. Currently, there are greatly advanced studies in the field of cost-analysis studies in this cancer [18-20]. On the other hand, the third new cases of cancer in females worldwide is cervical cancer [1], but the knowledge concerning salvage treatment including additional chemotherapy or targeted therapy still require further investigation. Whether this treatment may have some benefit, the cost-effectiveness of this targeted therapy should also be considered as seen in the issue with Trastusumab.

\section{Conclusion}

In conclusion, serum VEGF demonstrates some advantages for using it in locally advanced cervical cancer. Based on our results, the most benefit for this serum as a predictive factor may be seen in patients with stage IIIB. In this stage, patients with high serum VEGF level, > $825.6 \mathrm{pg} / \mathrm{ml}$, have a higher chance of treatment failure and death rate compared to patients in the same stage with serum VEGF level $\leq 825.6 \mathrm{pg} / \mathrm{ml}$. However, some questions regarding this serum still exist. We need more studies to confirm the role of serum VEGF as a predictive factor as well as the role of VEGF targeted-therapy in appropriate patients to improve the most efficient treatment outcomes. 


\section{Acknowledgements}

The authors gratefully acknowledge the financial support provided by the medical research fund of Faculty of Medicine Vajira Hospital, Navamindradhiraj University.

\section{REFERENCES}

[1] A. Jemal, F. Bray, M. M. Center, J. Ferlay, E. Ward and D. Forman, "Global Cancer Statistics," CA: A Cancer Journal for Clinicians, Vol. 61, No. 2, 2011, pp. 69-90. http://dx.doi.org/10.3322/caac.20107

[2] R. Pearcey, M. Brundage, P. Drouin, J. Jeffery, D. Johnston, H. Lukka, et al., "Phase III Trial Comparing Radical Radiotherapy with and without Cisplatin Chemotherapy in Patients with Advanced Squamous Cell Cancer of the Cervix," Journal of Clinical Oncology, Vol. 20, No. 4, 2002, pp. 966-972. http://dx.doi.org/10.1200/JCO.20.4.966

[3] Chemoradiotherapy for Cervical Cancer Meta-Analysis Collaboration, "Reducing Uncertainties about the Effects of Chemoradiotherapy for Cervical Cancer: A Systematic Review and Meta-Analysis of Individual Patient Data from 18 Randomized Trials," Journal of Clinical Oncology, Vol. 26, No. 35, 2008, pp. 5802-5812. http://dx.doi.org/10.1200/JCO.2008.16.4368

[4] P. Carmeliet and R. K. Jain, "Angiogenesis in Cancer and Other Diseases," Nature, Vol. 407, No. 6801, 2000, pp. 249-257. http://dx.doi.org/10.1038/35025220

[5] J. D. Carpini, A. K. Karam and L. Montgomery, "Vascular Endothelial Growth Factor and Its Relationship to the Prognosis and Treatment of Breast, Ovarian and Cervical Cancer," Angiogenesis, Vol. 13, No. 1, 2010, pp. 43-58. http://dx.doi.org/10.1007/s10456-010-9163-3

[6] H. S. Moon, S. C. Kim, J. J. Aha and B. H. Woo, "Concentration of Vascular Endothelial Growth Factor (VEGF) and Transforming Growth Factor- $\beta 1$ (TGF- $\beta 1$ ) in the Serum of Patients with Cervical Cancer: Prediction of Response," International Journal of Gynecological Cancer, Vol. 10, No. 2, 2000, pp. 151-156. http://dx.doi.org/10.1046/j.1525-1438.2000.00013.x

[7] X. P. Peng, J. D. Li, M. D. Li, X. M. Ye and W. C. Yan, "Clinical Significance of Vascular Endothelial Growth Factor in Sera of Patients with Gynecological Malignant Tumors," Chinese Journal of Cancer, Vol. 21, 2002, pp. 181-185.

[8] A. Lebrecht, E. Ludwig, A. Huber, M. Klein, C. Schneeberger, C. Tempfer, et al., "Serum Vascular Endothelial Growth Factor and Serum Leptin in Patients with Cervical Cancer," Gynecologic Oncology, Vol. 85, No. 1, 2002, pp. 32-35. http://dx.doi.org/10.1006/gyno.2001.6517

[9] B. Bachtiary, E. Selzer, T. H. Knocke, R. Potter and A. Obermair, "Serum VEGF Levels in Patients Undergoing Primary Radiotherapy for Cervical Cancer: Impact on Progression-Free Survival," Cancer Letters, Vol. 179, No. 2, 2002, pp. 197-203. http://dx.doi.org/10.1016/S0304-3835(01)00872-2
[10] S. P. Mathur, R. S. Mathur, E. A. Gray, D. Lane, P. G Underwood, M. Kohler, et al., "Serum Vascular Endothelial Growth Factor C (VEGF-C) as a Specific Biomarker for Advanced Cervical Cancer: Relationship to InsulinLike Growth Factor II (IGF-II), IGF Binding Protein 3 (IGF-BP3) and VEGF-B," Gynecologic Oncology, Vol. 98, No. 3, 2005, pp. 467-483. http://dx.doi.org/10.1016/j.ygyno.2005.05.003

[11] P. L. M. Zusterzeel, P. N. Span, M. G. K. Dijksterhuis, C. M. G. Thomas, F. C. G. J. Sweep and L. F. A. G. Massuger, "Serum Vascular Endothelial Growth Factor: A Prognos- tic Factor in Cervical Cancer," Journal of Cancer Re-search and Clinical Oncology, Vol. 135, No. 2, 2009, pp. 283-290. http://dx.doi.org/10.1007/s00432-008-0442-y

[12] S. Srivastava, A. Gupta, G. G. Agarwal, S. M. Natu, S. Uma, M. M. Goel, et al., "Correlation of Serum Vascular Endothelial Growth Factor with Clinicopathological Parameters in Cervical Cancer," Bioscience Trends, Vol. 3, 2009, pp. 144-150.

[13] K. Katanyoo, A. Chantarasri, M. Chongtanakon, K. Rongsriyam and T. Tantivatana, "Pretreatment Levels of Serum Vascular Endothelial Growth Factor Do Not Correlate with Outcome in Patients with Locally Advanced Cervical Cancer," Asian Pacific Journal of Cancer Prevention, Vol. 12, No. 3, 2011, pp. 1-6.

[14] M. Biedka, R. Makarewicz, A. Marzalek, H. Kardymowicz and A. Goralewska, "Labeling in Microvessel Density, Lymphatic Vessel, Density and Potential Role of Proangiogenic and Lymphangiogenic Factors as a Predictive/Prognostic Factors after Radiotherapy in Patients with Cervical Cancer," European Journal of Gynaecological Oncology, Vol. 33, No. 4, 2012, pp. 399-405.

[15] A. Gadducci, R. Tana, S. Cosio and A. R. Genazzani, "The Serum Assay of Tumour Markers in the Prognostic Evaluation, Treatment Monitoring and Follow-Up of Patients with Cervical Cancer: A Review of the Literature," Critical Reviews in Oncology/Hematology, Vol. 66, No. 4, 2008, pp. 10-20. http://dx.doi.org/10.1016/j.critrevonc.2007.09.002

[16] F. Forni, G. Ferrandina, F. Deodato, G. Macchia, A. G. Morganti, D. Smaniotto, et al., "Squamous Cell Carcinoma Antigen in Follow-Up of Cervical Cancer Treated with Radiotherapy: Evaluation of Cost-Effectiveness," International Journal of Radiation Oncology, Biology, Physics, Vol. 69, No. 4, 2007, pp. 1145-1149. http://dx.doi.org/10.1016/j.ijrobp.2007.04.055

[17] R. A. Burger, "Role of Vascular Endothelial Growth Factor Inhibitors in the Treatment of Gynecologic Malignancies," Journal of Gynecologic Oncology, Vol. 21, No. 1, 2010, pp. 3-11. http://dx.doi.org/10.3802/jgo.2010.21.1.3

[18] L. P. Garrison, D. Lubeck, D. Lalla, V. Paton, A. Dueck and E. A. Perez, "Cost-Effectiveness Analysis of Trastuzumab in the Adjuvant Setting for Treatment of HER2Positive Breast Cancer," Cancer, Vol. 110, No. 3, 2007, pp. 489-498. http://dx.doi.org/10.1002/cncr.22806 
[19] N. L. Liberato, M. Marchetti and G. Barosi, "Cost Effectiveness of Adjuvant Trastuzumab in Human Epidermal Growth Factor Receptor 2-Positive Breast Cancer," Journal of Clinical Oncology, Vol. 25, No. 22, 2007, pp. 625633. http://dx.doi.org/10.1200/JCO.2006.06.4220
[20] J. Norum, "The Cost-Effectiveness Issue of Adjuvant Trastuzumab in Early Breast Cancer," Expert Opinion on Pharmacotherapy, Vol. 7, No. 12, 2006, pp. 1617-1625. http://dx.doi.org/10.1517/14656566.7.12.1617 